\title{
Ön çapraz bağ yaralanması sonrası cerrahi tedavide greft seçenekleri
}

\section{Graft options in surgical treatment after anterior cruciate ligament injury}

\author{
Metin Polat ${ }^{1}$, H. Uğur Gönç ${ }^{1}$, N. Reha Tandoğan ${ }^{1,2}$, Asım Kayaalp ${ }^{1,2}$ \\ ${ }^{1}$ Çankaya Ortopedi, Ankara \\ ${ }^{2}$ Ortoklinik, Ankara
}

Ön çapraz bağ (ÖÇB) yaralanmaları genç ve aktif popülasyonda sık görülen ortopedik bir sorundur. Çoğu genç ya da aktif hastalar cerrahi olarak tedavi edilir. Konservatif izlenen hastalar yüksek oranlarda tekrarlayan instabilite, sekonder menisküs yırtığı, osteoartrit ve gelecekte total diz artroplastisi açısından yüksek risk gösterir. ÖÇB rekonstrüksiyonu farklı greft materyallerinin yanı sıra farklı cerrahi tekniklerle gerçekleştirilebilir. ÖÇB cerrahisi sırasında klinik sonuçları etkileyen birkaç intraoperatif faktör (greft seçimi, tünel yerleşimi, greft tespit açısı, greft gerginliği, ön çapraz bağ kalıntılarının korunması, eşlik eden ligament/menisküs/kıkırdak hasarı) vardır. Bunlar arasında greft seçimi cerrahi sırasında ele alınabilecek en kritik fakat tartışmalı soru olabilir. Hastanın ÖÇB greft seçimini etkileyen birincil faktör cerrahın önerisi olduğundan, cerrahlar bilinçli bir seçimi kolaylaştırmak için bazı faktörleri göz önünde bulundurmalıdır. Her bir hastada en iyi greft seçimi için sınırlı kanıt vardır. Greft seçimi cinsiyet, yaş, aktivite düzeyi, aktivite türü, greft yetmezliği, komplikasyonlar ve hastanın beklentisi gibi birçok faktöre göre kişiselleştirilmelidir. Ek olarak, her hastaya en iyi greft seçeneğini sunabilmek için çeşitli greftlere, spesifik cerrahi prosedürlere ve her greftin avantaj ve dezavantajlarına hakim olunmalıdır.

Anahtar sözcükler: ön çapraz bağ; greft seçenekleri; hamstring tendon; patellar tendon; kuadriseps tendon; allogreft; sentetik greft
Anterior cruciate ligament tears (ACL) are common orthopedic injuries that most commonly affect young and active patients. Most young, active patients are treated surgically. Patients who are conservatively followed are at high risk for recurrent instability, secondary meniscal tear, osteoarthritis and total knee arthroplasty in the future. ACL reconstruction can be performed using a variety of different surgical techniques as well as different graft materials. There are several intraoperative factors (graft selection, tunnel position, graft fixation angle, initial graft tension, native tissue remnant preservation and concomitant ligament/ meniscus/cartilage injuries) affecting clinical outcomes in anterior cruciate ligament surgery. Among them, graft selection might be the most critical but controversial question for surgeons that can be addressed at the time of surgery. As the primary factor influencing a patient's choice for the $A C L$ graft is surgeon recommendation, surgeons have to consider several factors to facilitate an informed choice. There is limited evidence to choose the best graft for each patient. Graft selection should be individualized according to multiple factors such as gender, age, activity level and type of activity, graft failure, complications and patient's expectation. In addition, surgeons must be familiar with a variety of grafts, their specific surgical procedures, and the advantages and disadvantages of each graft to offer the best graft options for each patient.

Key words: anterior cruciate ligament; graft options; hamstring tendon; patellar tendon; quadriceps tendon; allograft; synthetic graft

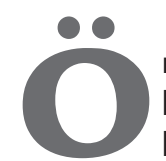

n çapraz bağ (ÖÇB) yaralanmaları; özellikle genç ve aktif popülasyonda en sık karşılaşılan bağ yaralanmasıdır. Bu genç ve aktif popülasyonda öncelikle instabiliteye bağlı artmış menisküs yırtığı, kondral yaralanma ve osteoartrit gelişimini en aza indirgemek için cerrahi tedavi tercih edilir. ${ }^{[1]}$ Tandoğan ve ark.'nın yaptığı çalışmada 764 ÖÇB rekonstrüksiyonu yapılan hastada ilk yaralanmayla cerrahi arasındaki süre ortalama 19,8 ay olarak bildirilmiş. Hastaların \%72,8'inde menisküs yırtığı tespit edilirken \%19,1'inde kondral hasar gözlenmiş. Illk yaralanma ile cerrahi arasındaki süre uzadıkça medial

- İletişim adresi: Dr. Asım Kayaalp, Ortoklinik, Cinnah Cad. 51/4 Çankaya, 06680, Ankara

Tel: 0532 -3263638 e-posta: askayaalp@gmail.com

- Geliș tarihi: 7 Nisan $2020 \quad$ Kabul tarihi: 30 Nisan 2020 


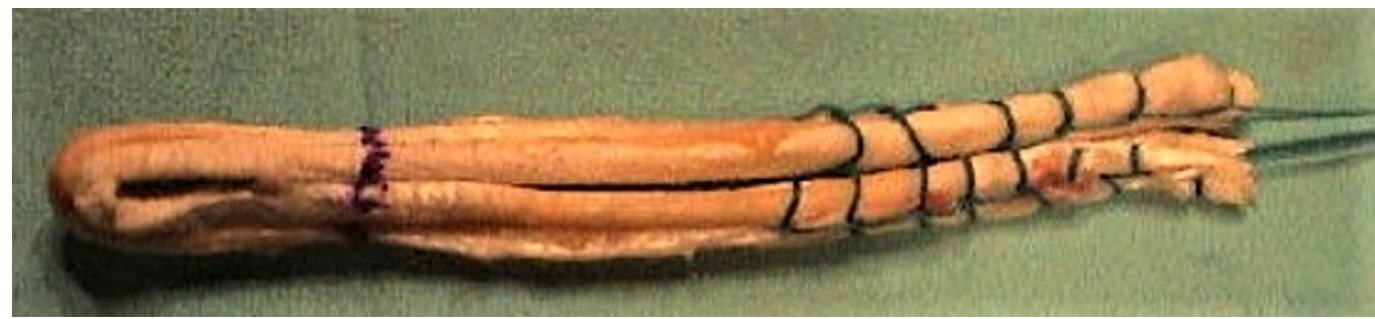

Şekil 1. Semitendinosus ve grasilis otogreftlerinin dört demet şeklinde hazırlanmış görünümü.

menisküs yırtığı ve kondral hasar görülme sıklığının arttığı bildirilmiştir. ${ }^{[2]}$ ÖÇB rekonstrüksiyonu yapılırken çeşitli cerrahi teknikler ve değişik greft seçeneklerinden yararlanılır. En iyi sonuçlar genel olarak dizin stabilitesinin sağlandığı hasta gruplarından elde edilir. Klinik sonuçları etkileyen birçok faktör varken bunlardan ameliyat sırasında olanlar; greft seçimi, tünel yerleşimi, greft tespit açısı, greft gerginliği, ön çapraz bağ kalıntılarının korunması, eşlik eden ligament/menisküs/kıkırdak hasarı varlı̆̆ıdır. Bunlar arasında en kritik ve tartışmalı olan greft seçimidir. Bir hastanın greft seçimini etkileyen en önemli faktör cerrahın önerisi olduğundan, cerrahlar bilinçli bir seçimi kolaylaştırmak için çeşitli faktörleri göz önünde bulundurmalıdır. Bunlar; greftin yeniden yırtılması (re-rüptürü) ve revizyon oranı, yaralanma öncesi aktivite düzeyine geri dönüş oranı, donör saha morbiditesi, gelecekteki osteoartrit riski, cerrahi süre, maliyet etkinliği ve greftlerle ilişkili komplikasyonlardır. Bunlarla birlikte cerrahın el alışkanlığı da greft seçimini etkilemektedir. ${ }^{[3]}$

Greft seçenekleri kabaca üç başlık altında incelenir: Otogreft, allogreft ve sentetik greftler. Otogreft seçenekleri hamstring tendonlar, patellar tendon, kuadriseps tendonu ve iliotibial banttır. İliotibial bant genellikle pediatrik ön çapraz bağ ve anterolateral ligament cerrahisinde kullanıldığından burada değinilmeyecektir. Allogreft seçenekleri: Tibialis posterior tendonu, aşil tendonu, tibialis anterior tendonu, kemik - patellar tendon - kemik ve peroneus longus tendonudur. En yaygın kabul gören sentetik greftler: LARS (Ligament Augmentation Reconstruction System) ve Leeds Keio'dur. ${ }^{[4]}$

$\mathrm{Bu}$ yazıda greft seçeneklerine ve karşılaştırmaIı çalışmalara tek tek değinilerek son güncel literatür eşliğinde cerrahların greft seçimini kolaylaştırmak hedeflenmektedir.

\section{HAMSTRING TENDON GREFTi}

ilk defa 1982 yılında kullanılmaya başlanan hamstring tendonları günümüzde ön çapraz bağ cerrahisinde en yaygın kullanılan greft seçeneğini oluşturmaktadır. ${ }^{[4]}$ Semitendinosus ve grasilis tendonlarının ikisi birden veya sadece semitendinosus tendonu alınarak tek veya çift bant ön çapraz bağ rekonstrüksiyonunda kullanılırlar (Şekil 1). Tek demet için hazırlanan greftin son kalınlığı 8 mm'nin üzerinde olması istenir. Yapılan çalışmalarda ince greftlerde yeniden yırtık oranının daha yüksek olduğu gösterilmiştir. ${ }^{[5]}$ Semitendinosus ikiye veya üçe katlanarak minimum $8 \mathrm{~mm}$ kalınlığında greft elde edilemiyorsa mutlaka grasilis tendonu da alınarak greft hazırlığına dahil edilmelidir. Hamstring tendonuyla ön çapraz bağ rekonstrüksiyonu yapılırken femoral ve tibial taraf tespiti için çeşitli implantlar (interferans vidası, kortikal düğme implantlar, cross-pin, staple, washer vb.) geliştirilmiştir. Kortikal düğme implantlarla femoral tespit yapılan hastalarda; ön çapraz bağın doğal insersiyonuyla tespit noktasının uzaklığının artmasına bağlı tünel genişlemesi bildirilmiş. Bu nedenle daha kısa tespit mesafesi oluşturmak için cross-pin implantları geliştirilmiş. Bununla birlikte, yakın zamanda yapılan bir meta-analiz, kortikal düğme implantlarla cross-pin tespiti arasında klinik ve fonksiyonel sonuçlarda hiçbir farklılık olmadığını göstermiştir. ${ }^{\left[{ }^{[]}\right.}$Seçilen tespit yönteminden bağımsız olarak yumuşak doku greftlerinin tünel içine adapte olması kemikli tendon greftine oranla altı haftaya kadar daha uzun sürebilmektedir. ${ }^{[7]}$

Hamstringlerle ön çapraz bağ rekonstrüksiyonunda düşük donör saha morbiditesi ve patellar tendonla rekonstrüksiyonda görülen kneeling, diz üstüne oturma ağrısı olmadığından her geçen gün daha popüler hale gelmiştir. Diğer taraftan hamstringlerin alınmasına bağlı dizde fleksiyon kuvvetinde eksiklik yaygın bir problemdir. Erken ameliyat sonrası dönemde bu kuvvetsizlik daha belirginken genellikle 3-6 ay arasında azalır. İki yıla kadar uzadığını bildiren çalışmalar da vardır. ${ }^{[8]}$ Diğer bir problem tendon alınırken safen sinirin infrapatellar ve sartoryal dalının yaralanmasına bağlı duyu kusurudur. İnsizyon yataya (transverse) yaklaştıkça bu risk artar. ${ }^{[9]}$ 


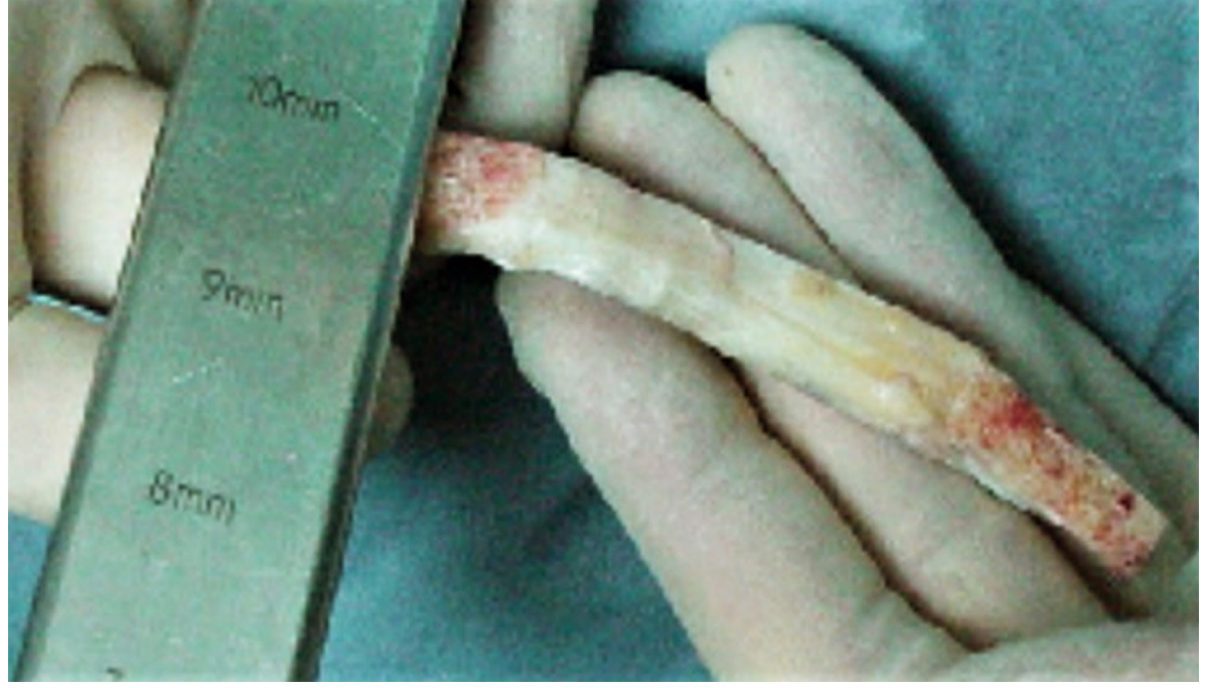

Şekil 2. Patellar tendonun alındıktan sonra hazırlanması.

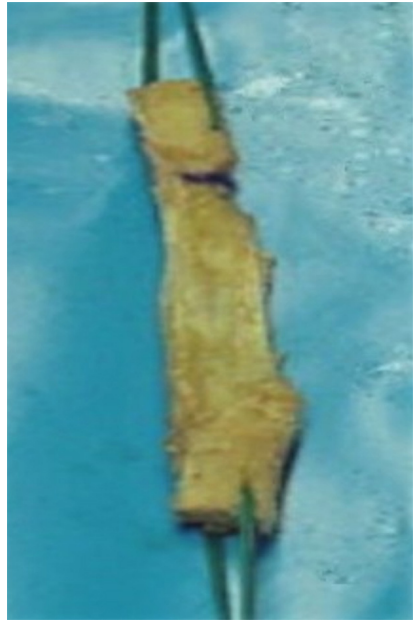

Şekil 3. Patellar tendonun rekonstrüksiyon yapılmadan önceki son görünümü.
Hamstring greftlerin uzun dönem takip sonuçlarını bildiren birçok çalışma başarıyı ya da başarısızlığı bildirmek için farklı kriterler kullanmışlardır. Leiter ve ark., hamstring tendonuyla rekonstrüksiyon yaptıkları 74 hastanın 14 yıllık sonuçlarını bildirdikleri çalışmalarında; \%75 hastanın IKDC (International Knee Documentation Committee, Uluslararası diz dökümantasyon komitesi) skorunu normal ya da normale yakın bulmuşlar. Radyografik incelemede opere olan tarafta \%19 oranında Kellgren-Lawrence Evre 3 osteoartrit saptanırken sağlam tarafta Evre 3 olanların oranı \%4 olarak belirtilmiştir. Bu farkın medial menisküs cerrahisinden kaynaklandığını bildirmişlerdir. Rekonstrüksiyon yapılan dizde yeniden yırtık oranı \%9 iken karşı dizde ön çapraz bağ yaralanma oranını $\% 5$ olarak bulmuşlardır. ${ }^{[4]}$

\section{KEMIK - PATELLAR TENDON - KEMIK OTOGREFTi}

Kemik - patellar tendon - kemik (KPTK) otogrefti (Şekil 2 ve 3) ön çapraz bağ rekonstrüksiyonlarının yaklaşık \%23'ünde kullanılmaktadır. ${ }^{[0]}$ KPTK otogrefti yüksek dayanıklılık ve sertlikte olması, kolay ulaşılabilir olması, biyomekanik özelliklerinin ön çapraz bağla benzemesi, interferans vidalarla solid bir tespit sağlanarak tünele daha hızlı ve kolay adapte olabilmesinden dolayı 1990'lara kadar ön çapraz bağ cerrahisinde altın standart olarak uygulanmıştır. Ancak donör saha morbiditesiyle ilişkili diz önü ağrısı ve kneeling ağrı ortaya çıkması, diz ekstansiyon kuvvetinde azalma, patella kırığı, patellar tendon yırtı ğı gibi komplikasyonlardan dolayı 1990'lı yıllardan itibaren hamstring tendonları daha yaygın kullanılır hale gelmiştir. ${ }^{[3]}$
Son zamanlarda anatomik ön çapraz bağ anlayışına uygun olarak ön çapraz bağ liflerinin doğal seyrini taklit etmek için femoral tünel dikdörtgen olarak hazırlanıp KPTK otogrefti o şekilde uygulanmaktadır. ${ }^{[11]}$ Bu tekniğin avantajları ön çapraz bağın liflerinin doğal seyrini taklit etmesi, greft ve tünelin temasını maksimum hale getirmesi ve interkondiler çentik anatomisini korumasıdır. Yapılan çalışmalarda yuvarlak yerine dikdörtgen açılmış femoral tünelin normal diz biyomekaniğine daha benzer özellikte olduğu gösterilmiştir. ${ }^{[12]}$

KPTK uygulanan hastaların uzun dönem sonuçları bazı yazarlar tarafından yayımlanmıştır. Mihelic ve ark., KPTK uyguladıkları 33 hastanın 17-20 yıllık takiplerinde \%83 hastanın IKDC skorlarının normal ya da normale yakın olduğunu bildirirken greft re-rüptür oranlarını vermemişlerdir. Gerhard ve ark., 63 hastanın ortalama 16 yıllık takiplerini bildirmişlerdir. IKDC skoru \%78 oranında normal veya normale yakın olarak bulunmuştur. Osteoartritik değiş̧iklikler hastaların \%19'unda varken, \%1,6 hasta revizyon ön çapraz bağ rekonstrüksiyonu gerektirmiştir. ${ }^{[4]}$

\section{HAMSTRING TENDON KPTK KARŞILAŞTIRMASI}

Ameliyat sonrası dönemde ön çapraz bağ rekonstrüksiyonu sonuçlarını değerlendirmek için genellikle IKDC ve Lysholm skorlamaları kullanılır. Sajovic ve ark. randomize kontrollü yaptıkları çalışmada, hamstring ve KPTK ile ön çapraz bağ rekonstrüksiyonu yaptıkları 64 hastayı 17 yıl takip ederek sonuçlarını yayımladılar. Lysholm skorları hamstring yapılan grupta (32 hasta) \%94 iken KPTK yapılan grupta (32 hasta) ise \%93 
olarak bildirilmiş. ${ }^{[13]} \mathrm{Bu}$ çalışmada olduğu gibi birçok meta-analiz ve derlemede hamstring ve KPTK yapılanlar arasında IKDC ve Lysholm skorları arasında fark bulunmamıştır. ${ }^{[14,15]}$

Hamstring tendonu ve KPTK arasında re-rüptür ve revizyon gereksinimi açısından hala bir fikir birliği bulunmamakla birlikte İskandinav ülkelerinin kayıtlarından yapılan çalışmalarda hamstring tendonunun re-rüptür oranı KPTK tendonundan daha fazla olduğu gösterilmiştir. ${ }^{[16,17]}$ Salem ve ark., 15-25 yaş aralığında ön çapraz bağ yaralanması nedeniyle hamstring veya KPTK grefti kullanarak rekonstrüksiyon yaptıkları genç kadın atletlerin sonuçlarını incelemişlerdir. Birinci grubu $15-20$ yaş aralığı oluştururken, $20-25$ yaş aralığı diğer grubu oluşturmuştur. En az iki $(2,6-5,4)$ yıl izledikleri 256 hastadan 175'ine KPTK greftiyle rekonstrüksiyon yapılmışken; 81'inde hamstring tendonları kullanılmıştır. Hamstring tendonları ile yapılanların \%22'si (18 hasta) 8 mm'den ince olduğundan allogreft ile güçlendirilmiştir. KPTK yapılan 175 hastadan 12 'sinde $(\% 6,9)$ re-rüptür olmuş, hamstring tendonları ile yapılan 81 hastadan 11'inde $(\% 13,6)$ re-rüptür olmuş. Bu gruptaki dört hasta allogreftle güçlendirilen hastalardan oluşmaktadır. İki yaş grubu kıyaslandığında re-rüptüre olan hamstring grubunun \%100'ü 15-20 yaş aralığındayken; KPTK yapılanlarda olguların \%75'inin bu yaş aralığında olduğu görülmüştür. Bu yaş grubunda re-rüptür (yeniden yırtık) oranı KPTK grubunda $\% 6,4$ bulunurken, hamstring grubunda $\% 17,5$ olarak bildirilmiştir. Sonuç olarak spor yapan 15-20 yaş aralığındaki kadın sporcularda KPTK daha güvenli bulunmuş. ${ }^{[18]}$ Meta-analiz, derleme veya ileriye dönük yapılan çalışmaların çoğunda yeniden yırtık (rerüptür) oranları arasında fark çıkmamıştır. ${ }^{[14,15]}$ Fakat Samuelsen ve ark.'nın yaptığı meta-analizde hamstring tendonunun re-rüptüründe KPTK'ye göre minimal artmış risk bulmuşlardır. ${ }^{[19]}$

Ön çapraz bağı yaralanmış dizlerde instabilite anterior veya rotatuvar laksite şeklinde olabilir. Anterior laksite en iyi olarak "Lachman" testiyle anlaşılabilir. Kantitatif olarak ise KT-1000 cihazıyla ölçüm yapılabilir. İnstabilitenin tespit edildiği diğer test pivot shift testidir. Hastalar tarafindan bildirilen instabilite varlığında Lachman ve KT-1000'den daha üstün olduğu gösterilmiştir. Her iki test mutlaka sağlam dizle karşılaştırmalı olarak bakılmalıdır. İnstabilite varlığının osteoartritle ilişkili olduğu gösterilmiştir. ${ }^{[3]}$ Mevcut güncel meta-analizler ve derlemelerde her iki greft arasında anterior laksite, Lachman ve enstrümanlarla yapılan laksite ölçümlerinde anlamlı fark bulunamamıştır. ${ }^{[14,15,19]}$ Pivot shift testi için mevcut meta-analizler ve derlemelerde her iki greft arasında anlamlı fark gösterilememiştir. ${ }^{[14,15]}$ Ancak Samuelsen ve ark., yaptıkları meta-analizde heterojen bir makaleyi çalışma dışı bıraktıklarında pivot shift testinin KPTK yapılan grupta daha düşük oranda pozitif olduğunu bildirmişlerdir. ${ }^{[19]}$

Ön çapraz bağ rekonstrüksiyonun asıl amacı; ön çapraz bağ yaralanması sonucu oluşabilecek posttravmatik artritten korunmaktır. Jones ve Spindler yedi akademik medikal merkezden 14 spor cerrahının yaptığı 1512 ön çapraz bağı kopuk olan hastanın 2-6 yıllık takiplerinde eklem aralığının daralıp osteoartrit gelişimi için risk faktörü olarak menisküsün durumu ve kıkırdak hasarının belirleyici olduğunu bildirmişler. Greft seçimini osteoartrit gelişiminde etkili bulmamışlar. $^{[20]}$ Ancak güncel meta-analiz ve derlemelerde her iki greft karşılaştıııldığında KPTK otogreftinde patellofemoral ve tibiofemoral artrit olasılığı hamstring grubuna oranla daha yüksek bildirilmiştir. ${ }^{[14,21]}$ Sajovic ve ark.'nın yaptığı her iki grubun 17 yıllık sonucunun karşılaştırıldığı randomize kontrollü çalışmada KPTK ile yapılan rekonstrüksiyonda osteoartrit gelişiminin daha fazla olduğu bildirilmiş. ${ }^{[13]}$ Mevcut literatür ışığında fark olmadığını veya KPTK greftinde riskin biraz daha fazla olduğunu söyleyen çalışmalar olduğundan gelecekte iki yöntemi kıyaslayacak daha homojen ileriye dönük çalışmalara ihtiyaç vardır.

Ön çapraz bağ rekonstrüksiyonu sonrası enfeksiyon nadir görülmekle birlikte çoklu debridman ameliyatları, uzun süre antibiyotik kullanımı, daha nadir olarak greftin kaybedilmesi ve revizyon gerekliliğine kadar gidebilecek can sıkıcı bir sorundur. Genel olarak görülme sıklığı $\% 0,14$ ile 1,7 aralığındadır. Bansal ve ark. yaptıkları meta-analizde hamstring tendonuyla yapılan rekonstrüksiyon sonrası enfeksiyon riskini KPTK'ye göre daha yüksek bildirmişler. Otogreft ve allogreft kıyaslandığında enfeksiyon oranları benzer olarak bildirilmiş. ${ }^{[22]}$

Ön çapraz bağ yaralanmaları genç ve profesyonel sporcularda görülen yaygın bir problemdir. Bu hasta popülasyonu için ne zaman tekrar spora dönecekleri veya tekrar aynı seviyede spor yapıp yapamayacakları önemli bir konudur. Sporcunun yaralanma öncesi seviyesine dönüşünü etkileyen birçok faktör varken; greft seçiminin önemi mevcut literatürde kısmen belirsizdir. Xie ve ark.'nın yaptığı meta-analizde ${ }^{[15]}$ KPTK ile yapılan rekonstrüksiyon sonucu daha erken spora döndükleri söylenirken, başka bir güncel meta-analizde ${ }^{[14]}$ her iki greft tipi arasında spora dönüşte fark olmadığı bildirilmektedir.

Her iki greft yapılan ön çapraz bağ rekonstrüksiyonlarında kas gücünü değerlendiren çalışmalar literatürde mevcuttur. Mevcut kas kuvvetini belirleyen en önemli faktör greftin alındığı bölgedir. KPTK greftinde ekstansör kas kuvvetinde kayıp olurken; hamstring 


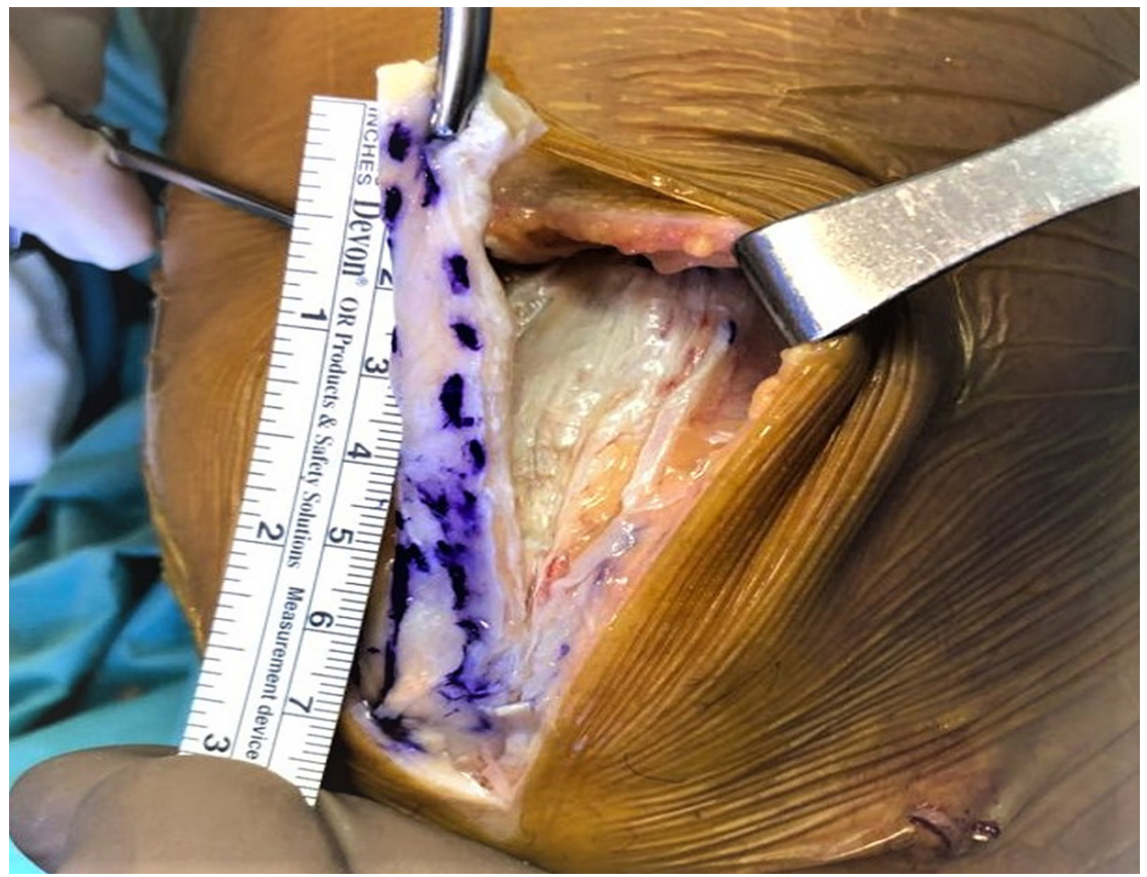

Şekil 4. Kuadriseps tendonunun alınma aşaması.

tendonları ile yapılan hastalarda yüksek fleksiyon derecelerinde fleksör kas kuvvet kaybı olmaktadır. Bazı spesifik sporlarda (judo, bale vb.) yüksek fleksiyon derecelerinde fleksör kas kuvveti ihtiyacı olduğundan rekonstrüksiyon için hamstring tendon kullanımından kaçınılmalıdır. ${ }^{3]}$

Radyografik tünel genişlemesini değerlendiren çaIışmaların çoğu hamstring tendon greftlerinin hem femoral hem de tibial tarafta KPTK greftine göre daha fazla oranda tünel genişlemesine neden olduğunu göstermiştir. Ancak yapılan çalışmalarda tünel genişlemesiyle diz laksitesi ve fonksiyonel skorlar arasında bir ilişki bulunamamıştır. Hamstring tendonuyla yapılan ön çapraz bağ rekonstrüksiyonlarında femoral tünelin anteriora doğru genişlediği akılda tutularak greft yerleşimi ona göre seçilmelidir. ${ }^{[3]}$

\section{KUADRISEPS OTOGREFTi}

Kuadriseps tendonu ön çapraz bağ rekonstrüksiyonlarında en az tercih edilen otogreft olmasına rağmen her geçen gün çıkan yeni makalelerle popülaritesi artmaktadır. Kemikli veya sadece tendon olarak hazırlanabilir (Şekil 4). Kuadriseps tendonunun avantajları; mini insizyonla ulaşılabilmesi, diz önü ağrısı ve kneeling ağrısının daha az olması, hamstring tendonlarına kıyasla fleksiyon kuvvetinde azalma yapmaması, istenirse greftin kemikli olarak hazırlanarak tünelde kemik-kemik iyileşme sağlanabilmesidir. ${ }^{[3]}$ Histolojik olarak kesit alanı başına patellar tendon \%20 daha fazla fibril içerirken, greftin modulusu hamstring ve KPTK greftine kıyasla daha fazla oranda ön çapraz bağa benzer bulunmuştur. Kalan kuadriseps tendonu hala intakt patellar tendondan \%80 daha güçlü olduğu bildirilmiştir. ${ }^{[23]}$ Hamstring tendonu ve KPTK greftine kıyasla mevcut kesi safen sinirin infrapatellar dalına uzak olduğundan uyuşukluk hissinin görülme ihtimali daha az ve patellar tendonu alınan hastalara kıyasla yara yerinde daha az skar ihtimali olduğu da bildirilmiş. ${ }^{[24]}$

Lund ve ark.'nın yaptığı ileriye dönük randomize kontrollü çalışmada 25 hastaya KPTK uygulanırken 26 hastaya kemik - kuadriseps tendonu (KKT) uygulanmış ve hastalar iki yıl takip edilmişler. Her iki grupta benzer fonksiyonel skor ve anterior stabilite elde edilirken, KKT grubunda greft yerinde ağrı ve uyuşuklukla birlikte kneeling ağrı daha az olmuştur. ${ }^{[25]}$ Lee ve ark. yaptıkları ileriye dönük çalışmada 48 hastanın ön çapraz bağını KKT ile rekonstrükte ederken 48 hastanınki çift demet hamstring tendonuyla rekonstrükte etmişlerdir. Bütün hastalar en az iki yıl takip edilmişler ve benzer diz stabilitesi ve fonksiyonel sonuçlar alınmasına rağmen fleksör kas gücü KKT grubunda daha iyi bulunmuştur. ${ }^{[26]}$ Cavaignac ve ark. yaptıkları ileriye dönük çalışmada 50 hastaya KKT ile anatomik 


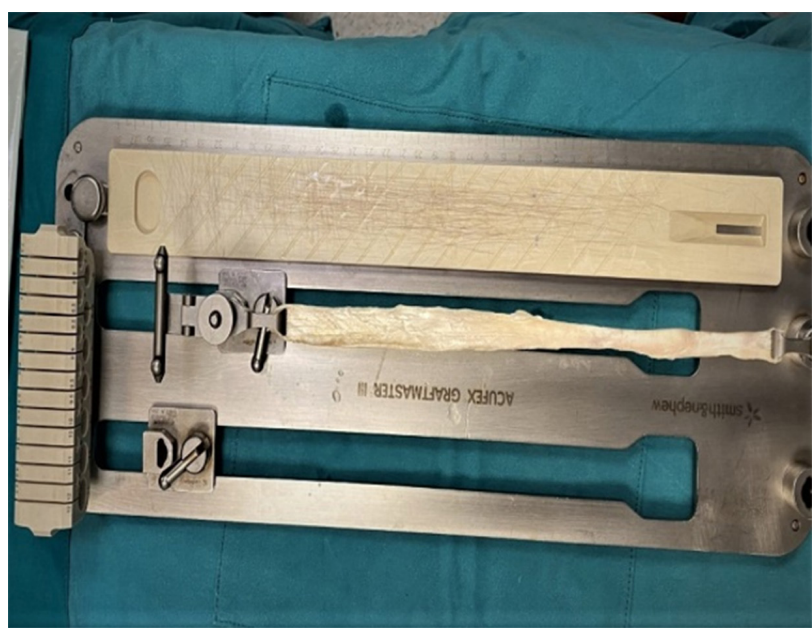

Şekil 5. Greft hazırlama tablasında peroneus longus allogreftinin görünümü.

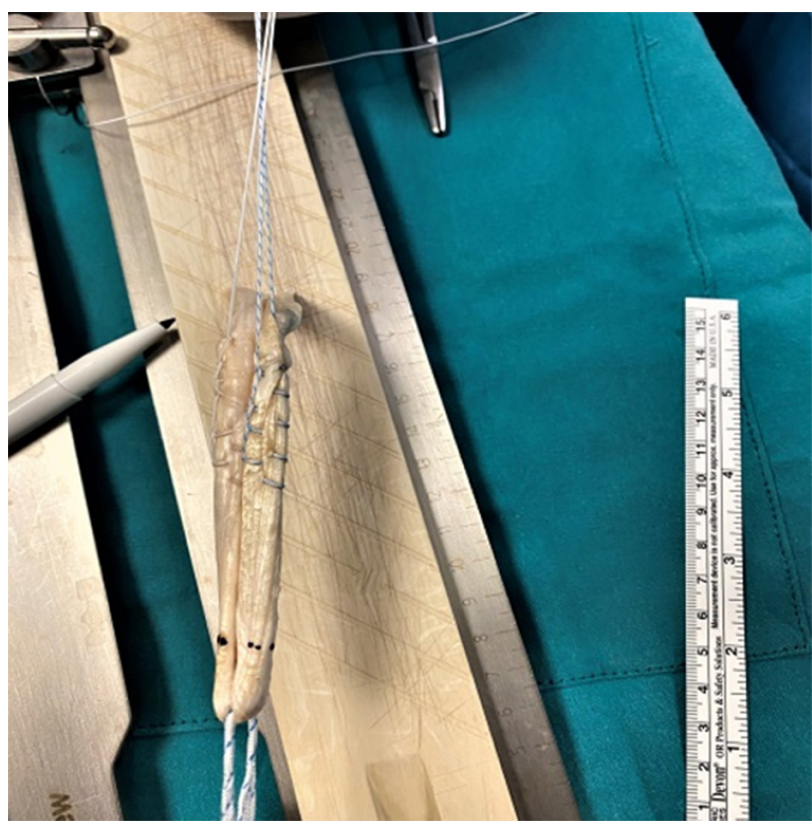

Şekil 6. Greft hazırlama tablasında peroneus longus allogreftinin katlandıktan sonra askı sistemiyle rekonstrüksiyon yapılmadan önceki son görünümü.

rekonstrüksiyon yapılırken 45 hastaya hamstring tendonuyla tek demet rekonstrüksiyon yapılmıştır. Seksen altı hasta (45 KKT, $41 \mathrm{HT}$ ) ortalama 3,6 yıl takip edilmiştir. Üç re-rüptür görülen hastanın biri KKT grubunda, iki hasta ise hamstring grubunda olarak belirlenmiştir. Bütün klinik skorlar (Lysholm, KOOS, KOOS sport) KKT grubunda daha iyi olarak değerlendirilmiştir. Dizin stabilitesini değerlendiren Lachman ve pivot shift testleri KKT grubunda daha az oranda pozitif olarak gözlenmiştir. ${ }^{[27]}$ Gagliardi ve

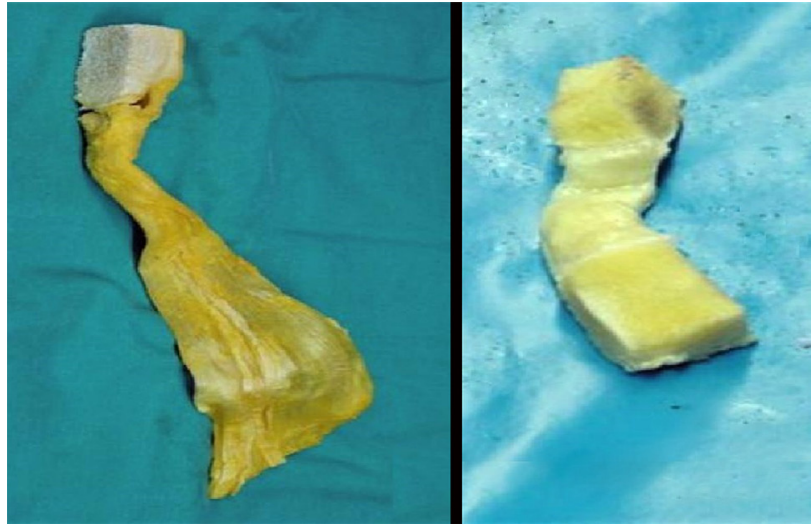

Şekil 7. Sol tarafta kemikli aşil allogrefti, sağ tarafta KPTK allogrefti görülmekte.

ark., KKT ile ön çapraz bağ rekonstrüksiyonu yaptıkları 10 ila 18 yaş arasındaki 81 hastanın sonuçlarını yayımlamışlardır. Otuz altı aylık takibin sonucunda greft re-rüptür oranını \%1,2 olarak bildirmişlerdir. Karşı dizde ön çapraz bağ yaralanması oranını \%9,9 olarak bildirmişlerdir. Hastaların \%87,9'u cerrahi sonrası spora dönebilmiştir. ${ }^{[28]}$

\section{ALLOGREFTLER}

Özellikle donör saha morbiditesi allogreft kullanımını gündeme getirmiş ve klasik hayvan çalışmaları, ardından klinik insan çalışmalarından sonra allogreftler ön çapraz bağ rekonstrüksiyonunda kullanılmaya başlanmış (Şekil 5-7). Donör saha morbiditesinin olmayışı, istenen ölçülerde greft boyutuna ulaşılabilirlik, daha kısa ameliyat süresi, çoklu bağ ve revizyon ameliyatlarında kullanım kolaylığı allogreftlerin avantajlarıdır. Dezavantajları ise; özellikle genç hastalarda otogreftlerle karşılaştırıldığında revizyon oranları daha yüksek, allogreftlerin tünele adaptasyon ve tekrar şekillenme süreci daha uzun ve zayıf, biyomekanik olarak daha dayanıksızdırlar. Ayrıca potansiyel immünolojik reaksiyon riski, hastalık taşınma ihtimali ve ekonomik olarak daha büyük bütçeler gerektirmesi endişe vericidir. Ancak allogreft kullanımı enfeksiyon ihtimalini artırmaz. Özellikle allogreftin 1,8 Mrad'dan daha yüksek dozlarda ışınlanması, düşük sıcaklıkta sporları öldürmek için kimyasallarla muamele edilmesi greftte yetmezlik ihtimalini artırmaktadır. ${ }^{[3]}$ Işınlanmamış ya da işlenmemiş allogreftlerin otogreftlerle benzer sonuçlar gösterdiğini bildiren çalışmalar olmakla birlikte Bottoni ve ark.'nın yaptığı randomize kontrollü çalışmanın 10 yıllık takibinde ışınlanmamış tibialis posterior allogreftinin hamstring otogreftine kıyasla üç kat daha fazla oranda 
re-rüptüre olduğu bildirilmiş. ${ }^{[29]}$ Allogreftlerin tercih edildiği hastalar; revizyon cerrahileri sonrasında mevcut otogreftleri sorunlu olanlar ve otogreftle ameliyat olmak istemeyen hastalardan oluşur. ${ }^{[3]}$

\section{SENTETIK GREFTLER}

Otogreftlerin donör saha morbiditesi, allogreftlerin başarısızlığı ve hastalık taşıma riski sentetik greftlerin gelişimine yol açmıştır. Sentetik greftler günümüzde üçüncü jenerasyon olarak üretilmektedir. Birinci ve ikinci kuşaklara karşı katastrofik debris ve sinovit meydana geldiğinden üçüncü jenerasyon geliştirilmiştir. ${ }^{[4]}$ Tünel genişlemesi, tekrarlayan ağrı, mekanik yetmezlik ve enfeksiyon erken jenerasyon sentetik greftlerin diğer komplikasyonlarıdır. ${ }^{[3]}$ Üçüncü jenerasyon sentetik greftlerden olan LARS (Ligament Augmentation and Reconstruction System, Arc-sur-Tille, France) polietilen tereftalattan yapılmış olup özel endikasyonlar için üretilmiştir. Diğer sentetik greftlere göre daha az yetmezlik, revizyon ve sinovit görülür. En yeni nesil sentetik greftlerin mantığı, yeni yaralanmış bir ön çapraz bağın iyileşmesini artırmak için kullanılmasıdır. Akut yaralanma sonrasında cerrahi en kısa zamanda yapılmalı ve ön çapraz bağ güdüğü korunarak femoral yapışma yerine çekilmeye çalışılarak greftin güçlendirilmesi sağlanmalıdır. ${ }^{[4]}$ LARS ve otogreftle karşılaştırılan çalışmalar tartışmalı olmakla birlikte daha geniş ve kapsamlı randomize kontrollü çalışmalara ihtiyaç vardır. ${ }^{[3]}$

\section{KAYNAKLAR}

1. Sanders TL, Pareek A, Kremers HM, Bryan AJ, Levy BA, Stuart MJ, Dahm DL, Krych AJ. Long-term follow-up of isolated ACL tears treated without ligament reconstruction. Knee Surg Sports Traumatol Arthrosc 2017;25(2):493-500. Crossref

2. Tandogan RN, Taşer O, Kayaalp A, Taşkiran E, Pinar H, Alparslan B, Alturfan A. Analysis of meniscal and chondral lesions accompanying anterior cruciate ligament tears: relationship with age, time from injury, and level of sport. Knee Surg Sports Traumatol Arthrosc 2004;12(4):262-70. Crossref

3. Koga $H$, Zaffagnini S, Getgood AM, Muneta T. ACL graft selection: state of the art. J ISAKOS: Joint Disord Orthop Sports Med 2018;3(3):177-84. Crossref

4. Shaerf DA, Pastides PS, Sarraf KM, Willis-Owen CA. Anterior cruciate ligament reconstruction best practice: A review of graft choice. World J Orthop 2014;5(1):23-9. Crossref

5. Conte EJ, Hyatt AE, Gatt CJ Jr, Dhawan A. Hamstring autograft size can be predicted and is a potential risk factor for anterior cruciate ligament reconstruction failure. Arthroscopy 2014;30(7):882-90. Crossref

6. Jiang H, Ma G, Li Q, Hu Y, Li J, Tang X. Cortical Button Versus Cross-pin Femoral Fixation for Hamstring Anterior Cruciate Ligament Reconstruction: A Meta-analysis of Randomized Controlled Trials. Am J Sports Med 2018;46(9):2277-84. Crossref

7. Widner M, Dunleavy M, Lynch S. Outcomes Following ACL Reconstruction Based on Graft Type: Are all Grafts Equivalent? Curr Rev Musculoskelet Med 2019;12(4):460-5. Crossref
8. Konrath JM, Vertullo CJ, Kennedy BA, Bush HS, Barrett RS, Lloyd DG. Morphologic Characteristics and Strength of the Hamstring Muscles Remain Altered at 2 Years After Use of a Hamstring Tendon Graft in Anterior Cruciate Ligament Reconstruction. Am J Sports Med 2016;44(10):2589-98. Crossref

9. Hardy A, Casabianca L, Andrieu K, Baverel L, Noailles T; the Junior French Arthroscopy Society. Complications following harvesting of patellar tendon or hamstring tendon grafts for anterior cruciate ligament reconstruction: Systematic review of literature. Orthop Traumatol Surg Res 2017;103(8):S2458. Crossref

10. Tibor L, Chan PH, Funahashi TT, Wyatt R, Maletis GB, Inacio MC. Surgical Technique Trends in Primary $A C L$ Reconstruction from 2007 to 2014. J Bone Joint Surg Am 2016;98(13):1079-89. Crossref

11. Shino K, Nakata K, Nakamura N, Toritsuka $Y$, Nakagawa $S$, Horibe S. Anatomically oriented anterior cruciate ligament reconstruction with a bone-patellar tendon-bone graft via rectangular socket and tunnel: a snug-fit and impingementfree grafting technique. Arthroscopy 2005;21(11):1402.e15. Crossref

12. Suzuki $T$, Shino $K$, Otsubo $H$, Suzuki D, Mae T, Fujimiya $M$, Yamashita $\mathrm{T}$, Fujie $\mathrm{H}$. Biomechanical comparison between the rectangular-tunnel and the round-tunnel anterior cruciate ligament reconstruction procedures with a bone-patellar tendon-bone graft. Arthroscopy 2014;30(10):1294-302. Crossref

13. Sajovic M, Stropnik D, Skaza K. Long-term Comparison of Semitendinosus and Gracilis Tendon Versus Patellar Tendon Autografts for Anterior Cruciate Ligament Reconstruction: A 17-Year Follow-up of a Randomized Controlled Trial. Am J Sports Med 2018;46(8):1800-8. Crossref

14. Poehling-Monaghan KL, Salem H, Ross KE, Secrist E, Ciccotti MC, Tjoumakaris F, Ciccotti MG, Freedman KB. Long-Term Outcomes in Anterior Cruciate Ligament Reconstruction: A Systematic Review of Patellar Tendon Versus Hamstring Autografts. Orthop J Sports Med 2017;5(6):232596711770973. Crossref

15. Xie X, Liu X, Chen Z, Yu Y, Peng S, Li Q. A meta-analysis of bone-patellar tendon-bone autograft versus four-strand hamstring tendon autograft for anterior cruciate ligament reconstruction. Knee 2015;22(2):100-10. Crossref

16. Gifstad T, Foss OA, Engebretsen L, Lind M, Forssblad M, Albrektsen G, Drogset JO. Lower risk of revision with patellar tendon autografts compared with hamstring autografts: a registry study based on 45,998 primary ACL reconstructions in Scandinavia. Am J Sports Med 2014;42(10):2319-28. Crossref

17. Persson A, Fjeldsgaard $K$, Gjertsen JE, Kjellsen $A B$, Engebretsen L, Hole RM, Fevang JM. Increased risk of revision with hamstring tendon grafts compared with patellar tendon grafts after anterior cruciate ligament reconstruction: a study of 12,643 patients from the Norwegian Cruciate Ligament Registry, 2004-2012. Am J Sports Med 2014;42(2):285-91. Crossref

18. Salem HS, Varzhapetyan V, Patel N, Dodson CC, Tjoumakaris FP, Freedman KB. Anterior Cruciate Ligament Reconstruction in Young Female Athletes: Patellar Versus Hamstring Tendon Autografts. Am J Sports Med 2019;47(9):2086-92. Crossref

19. Samuelsen BT, Webster KE, Johnson NR, Hewett TE, Krych AJ. Hamstring Autograft versus Patellar Tendon Autograft for ACL Reconstruction: Is There a Difference in Graft Failure Rate? A Meta-analysis of 47,613 Patients. Clin Orthop Relat Res 2017;475(10):2459-68. Crossref 
20. Jones $\mathrm{MH}$, Spindler KP. Risk factors for radiographic joint space narrowing and patient reported outcomes of posttraumatic osteoarthritis after ACL reconstruction: Data from the MOON cohort. J Orthop Res 2017;35(7):1366-74. Crossref

21. Xie X, Xiao Z, Li Q, Zhu B, Chen J, Chen H, Yang F, Chen $Y$, Lai Q, Liu X. Increased incidence of osteoarthritis of knee joint after $A C L$ reconstruction with bone-patellar tendonbone autografts than hamstring autografts: a meta-analysis of 1,443 patients at a minimum of 5 years. Eur J Orthop Surg Traumatol 2015;25(1):149-59. Crossref

22. Bansal A, Lamplot JD, VandenBerg J, Brophy RH. Metaanalysis of the Risk of Infections After Anterior Cruciate Ligament Reconstruction by Graft Type. Am J Sports Med 2018;46(6):1500-8. Crossref

23. Xerogeanes JW. Quadriceps Tendon Graft for Anterior Cruciate Ligament Reconstruction: THE GRAFT OF THE FUTURE! Arthroscopy 2019;35(3):696-7. Crossref

24. Mouarbes D, Dagneaux L, Olivier M, Lavoue V, Peque E, Berard E, Cavaignac E. Lower donor-site morbidity using QT autografts for ACL reconstruction. Knee Surg Sports Traumatol Arthrosc 2020. Crossref
25. Lund $B$, Nielsen $T$, Faunø $P$, Christiansen $S E$, Lind $M$. Is quadriceps tendon a better graft choice than patellar tendon? a prospective randomized study. Arthroscopy 2014;30(5):593-8. Crossref

26. Lee JK, Lee S, Lee MC. Outcomes of Anatomic Anterior Cruciate Ligament Reconstruction: Bone-Quadriceps Tendon Graft Versus Double-Bundle Hamstring Tendon Graft. Am J Sports Med 2016;44(9):2323-9. Crossref

27. Cavaignac E, Coulin B, Tscholl P, Nik Mohd Fatmy N, Duthon $V$, MenetreyJ. Is Quadriceps Tendon Autograft a Better Choice Than Hamstring Autograft for Anterior Cruciate Ligament Reconstruction? A Comparative Study with a Mean Follow-up of 3.6 Years. Am J Sports Med 2017;45(6):1326-32. Crossref

28. Gagliardi AG, Carry PM, Parikh HB, Albright JC. Outcomes of Quadriceps Tendon With Patellar Bone Block Anterior Cruciate Ligament Reconstruction in Adolescent Patients With a Minimum 2-Year Follow-up. Am J Sports Med 2020;48(1):93-8. Crossref

29. Bottoni CR, Smith EL, Shaha J, Shaha SS, Raybin SG, Tokish JM, Rowles DJ. Autograft Versus Allograft Anterior Cruciate Ligament Reconstruction: A Prospective, Randomized Clinical Study with a Minimum 10-Year Follow-up. Am J Sports Med 2015;43(10):2501-9. Crossref 